\title{
Production and modulation of interleukin 6 synthesis by synoviocytes derived from patients with arthritic disease
}

\author{
James T Rosenbaum, Regina Cugnini, David C Tara, Steve Hefeneider, John C Ansel
}

\begin{abstract}
Interleukin 6 (IL-6) is a potent cytokine, the biological activities of which include the stimulation of immunoglobulin secretion, $\mathbf{T}$ cell activation, induction of the acute phase response, activation of megakaryocytes, and pyrogenicity. These biological activities make it a plausible contributor to rheumatoid arthritis. The ability of synoviocytes to synthesise this potential mediator of inflammation was tested. Cultures of fibroblast-like cells were established from joint tissue from patients with rheumatoid arthritis, degenerative joint disease, or trauma. Supernatants from synoviocytes from each diagnostic category contained IL-6-like activity as detected in a B9 plasmacytoma cell proliferation assay. Supernatants from IL-1 stimulated synoviocytes from patients with rheumatoid arthritis $(n=5)$ contained an average of $70000 \mathrm{U} / \mathrm{ml}$ IL-6. Western blot analysis confirmed that these supernatants contained peptides that reacted with a highly specific antibody to IL-6. A cDNA probe specific for IL-6 hybridised with mRNA derived from synoviocytes representative of each disease state. Interleukin 6 mRNA expression increased by culturing synoviocytes in the presence of $10 \%$ calf serum, IL-1 (30 U/ml), insulin $(166 \mathrm{ng} / \mathrm{ml})$, or basic fibroblast growth factor $(16 \mathrm{ng} / \mathrm{ml})$. In contrast, dexamethasone $\left(10^{-6} \mathrm{~mol} / \mathrm{l}\right)$ suppressed the ability of IL-1 to increase the expression of IL-6 mRNA. Recombinant IL-6 itself did not detectably upregulate its own message. The regulation of production of IL-6 by synoviocytes may be important in the pathogenesis of joint inflammation.
\end{abstract}

The pathogenesis of rheumatoid arthritis is poorly understood. Cytokines are thought to contribute to the process of inflammation. For example, interleukin 1 (IL-1) is detectable in joint fluid ${ }^{1}$ and is produced by synoviocytes maintained in tissue culture. ${ }^{2}$ Furthermore, $^{2}$ synoviocytes proliferate in response to IL-1. The biological properties of IL-1 have suggested to many workers that it is an important contributor to inflammatory joint disease. ${ }^{4}$ These properties include the ability to stimulate lymphocytes, act as a chemoattractant, induce prostaglandin synthesis, and stimulate the acute phase response. 5

Recent evidence indicates that many of the biological properties formerly ascribed to IL-1 may be mediated by IL- $6 .^{67}$ This peptide is also known as interferon $\beta 2$, hepatocyte stimulating factor, $B$ cell stimulatory factor 2 , and hybridoma-plasmacytoma growth factor. ${ }^{8-10}$ Like IL-1, this cytokine acts as a pyrogen, ${ }^{7}$ stimulates the acute phase response, ${ }^{11}$ acts as a cofactor in $\mathrm{T}$ cell proliferation, ${ }^{12}$ and acts synergistically with IL-3 in stimulating the growth of haematopoietic stem cells. ${ }^{13}$ Interleukin 6 may also induce the synthesis of IL-1 ${ }^{14}$; and IL-1 may conversely induce the synthesis of IL-6. ${ }^{15}$

Interleukin 6 is synthesised by a variety of cell types including monocytes, fibroblasts, vascular endothelial cells, pancreatic $\beta$ cells and some tumour cell lines. ${ }^{16} 17$ In view of the interest in IL-1 as a mediator of joint inflammation and the contribution of the synoviocyte in this respect, we tested the ability of cultured synoviocytes from patients with rheumatoid arthritis, osteoarthritis, and joint trauma to synthesise IL-6. In addition, we examined the modulation of IL-6 in these synovial cells by cytokines, growth factors, and corticosteroids.

\section{Methods}

\section{SYNOVIOCYTE CULTURES}

Synovial tissue was obtained from patients with definite or classical rheumatoid arthritis, osteoarthritis, or joint trauma who were undergoing corrective surgery. After removal from the joint, the tissue was washed in Hanks's balanced salt solution (Gibco Laboratories). Synovial tissue was aseptically minced and resuspended in Dulbecco's modified Eagle's medium (Gibco) with $20 \%$ fetal calf serum (Gibco). Tissue was plated in Falcon $100 \mathrm{~mm}^{2}$ plates. After several days, non-adherent tissue was discarded, while adherent cells were maintained in culture. This resulted in the establishment of homogeneous synovial cell cultures as described by other workers. ${ }^{18} 19$ Primary cell cultures and cells of various ages in culture (2-30 months) were used for subsequent experiments.

PROLIFERATION ASSAY TO DETECT IL-6 BIOLOGICAL ACTIVITY

The presence of IL-6-like activity in the supernatants from cultured cells was determined by the ability of these supernatants to induce the proliferation of the murine $B 9$ plasmacytomas cell line ${ }^{20}$ (a generous gift of L. Aarden, University of Amsterdam). Five thousand B9 cells were cultured in RPMI 1640 medium supplemented with $5 \times 10^{-5}$ M 2-mercaptoethanol, 5\% fetal calf serum, penicillin, streptomycin, and either IL- 6 or the conditioned medium under study. The cells were pulsed with $37 \mathrm{kBq}$ of ${ }^{3} \mathrm{H}$-thymidine $68-72$ hours after 
plating in 96 well flat bottomed plates in a volume of $200 \mu \mathrm{l}$. Cells were harvested four to six hours after thymidine labelling and the amount of incorporated radioactivity was calculated. One unit of activity was defined as the amount resulting in half maximal stimulation by a standard preparation. This standard consisted of supernatant from cultured mononuclear cells that had been stimulated with IL-1. The standard preparation contained approximately $8000 \mathrm{U} / \mathrm{ml}$. All assay conditions were tested in triplicate:

\section{NORTHERN BLOT ANALYSIS}

Cultured cells were detached by treatment with cold phosphate buffered saline containing $0 \cdot 2 \%$ trypsin. Cells were washed twice with phosphate buffered saline to remove trypsin. Cells were lysed in iso-high buffer $(0 \cdot 14 \mathrm{M}$ sodium chloride, $10 \mathrm{mM}$ TRIS, $1.5 \mathrm{mM}$ magnesium chloride, $250 \mu \mathrm{g} / \mathrm{ml}$ heparin (Gibco), $250 \mu \mathrm{g} / \mathrm{ml}$ spermidine hydrochloride (USB), $\mathrm{pH} 8 \cdot 0$, containing 5\% NP-40. Nuclei were pelleted and RNA from the supernatant was purified by phenol-chloroform extraction and ethanol precipitation. In selected studies, polyadenosine enriched RNA was obtained by purification over an oligo-deoxythymidine column as previously described. ${ }^{21}$ The concentration of RNA was determined from the absorbance at $260 \mathrm{~nm}$, with the ratio of absorbance at $260 \mathrm{~nm}$ to absorbance at $280 \mathrm{~nm}$ being greater than $1 \cdot 7$. RNA was electrophoresed in $1.0 \%$ agarose gels containing $0.22 \mathrm{M}$ formaldehyde followed by capillary transfer of the RNA to $0.45 \mu \mathrm{m}$ pore size nitrocellulose (Schleicher and Schuell). Membranes were prehybridised for at least four hours with $0.04 \%$ bovine serum albumin, $50 \%$ formamide, $5 \times \operatorname{SSC}(0 \cdot 15 \mathrm{M}$ sodium chloride, $0.015 \mathrm{M}$ sodium citrate, $\mathrm{pH} \mathrm{7.0}$ ), salmon sperm DNA $(250 \mu \mathrm{g} / \mathrm{ml})$, and polyadenylated RNA $(50 \mu \mathrm{g} / \mathrm{ml})$. IL-6 mRNA was detected using a $1.0 \mathrm{~kb}$ EcoRI cDNA fragment ${ }^{22}$ (a generous gift of T Kishimoto, University of Osaka, Japan). This cDNA was ${ }^{32} \mathrm{P}$ labelled by random priming. Hybridisation was performed under identical conditions as for prehybridisation, except for the inclusion of the radiolabelled probe. Nonspecific binding was removed by washing four times for 10 minutes using $2 \times \mathrm{SSC}$ and $0.5 \%$ sodium dodecyl sulphate at $65^{\circ} \mathrm{C}$.

\section{WESTERN BLOT ANALYSIS}

Supernatants from synoviocyte cultures were dialysed against distilled water and then concentrated ten fold by lyophilisation. Concentrated supernatant $(1 \mu \mathrm{l})$ was separated by sodium dodecyl sulphate polyacrylamide gel electrophoresis (Pharmacia PHAST system) under reducing conditions. The proteins were passively transferred to Immobilon PVDF transfer membrane at $70^{\circ} \mathrm{C}$ over a period of 25 minutes. This blot was probed with a rabbit antiserum (generously provided by Lester May, Rockefeller University) directed against recombinant human IL-6. ${ }^{23}$ The rabbit antiserum was then detected by a goat-anti-rabbit IgG antibody conjugated to alkaline phosphatase (Tago). The same anti- serum was also used to characterise the bioactivity detected in the $\mathrm{B} 9$ proliferation assay described above. Prestained molecular weight markers (Biorad) were run as size standards.

\section{REAGENT}

Recombinant human IL- $1 \alpha$ was the generous gift of Peter Lomedico (Hoffmann-LaRoche, Nutley, NJ, USA) Recombinant human IL-6 was purchased from $R$ and D Systems. Basic fibroblast growth factor was a generous gift of Gary Shipley (Oregon Health Sciences University).

\section{Results}

To determine if synoviocytes were capable of secreting IL-6-like activity, supernatants from cultured synoviocytes from patients with rheumatoid arthritis, osteoarthritis, or trauma were tested for their ability to stimulate the proliferation of the IL- 6 responsive B9 mouse plasmacytoma cell line. Figure 1 , a representative study, shows that supernatant from synoviocytes derived from a patient with traumatic joint disease did induce detectable mitogenesis in the B9 cell line. The secretion of IL-6-like activity was enhanced by culturing the synoviocytes in the presence of IL-1. The effects of IL-1 were clearly dose dependent. Furthermore, the IL-1 effects were more marked after culture for 48 hours as opposed to 18 hours (data not shown). Interleukin 1 by itself did not induce the proliferation of B9 cells. The table shows that IL-6-like biological activity was detected from supernatants obtained from cells derived from patients with rheumatoid arthritis, osteoarthritis, or trauma. Several cultures representative of each diagnostic category were tested. No statiscally significant quantitative differences were apparent with respect to the diagnosis as judged by a Student's $t$ test $(\mathrm{p}>0.05)$ for unstimulated or IL-1 stimulated synthesis of IL-6.

To characterise further the IL-6 activity, we tested the ability of a polyclonal rabbit antiserum to IL-6 as an inhibitor of the mitogenic activity in supernatants from cultured synoviocytes. This antiserum markedly inhibited the ability of synoviocyte conditioned medium to stimulate B9 plasmacytoma cell proliferation. Figure 2 shows that supernatant from a synoviocyte culture derived from a patient with rheumatoid arthritis induced the proliferation of the B9 cell line. As was shown in fig 1 , supernatant from synoviocytes cultured in the presence of IL-1 ( $30 \mathrm{U} / \mathrm{ml}$ ) show an enhanced ability to stimulate mitogenesis of the $\mathrm{B} 9$ cell line. The antiserum to IL-6 at a dilution of either 1:50 or 1:100 inhibited the proliferative activity present in the supernatant from synoviocytes (fig 2). The partial inhibition of proliferative activity in conditioned medium from IL-1 stimulated synoviocytes indicates that the antiserum is not by itself toxic to plasmacytoma cells and is compatible with the concept that greater IL-6like activity is detectable after IL-1 stimulation.

To support further the hypothesis that supernatant from synoviocyte cultures contained IL-6, conditioned medium was tested for the 
presence of peptide reactive with antisera to IL-6 using Western blot analysis. Figure 3 shows that concentrated supernatant from synoviocytes cultured from a patient with rheumatoid arthritis, a patient with osteoarthritis, and a patient with traumatic joint disease contained peptides of approximate molecular

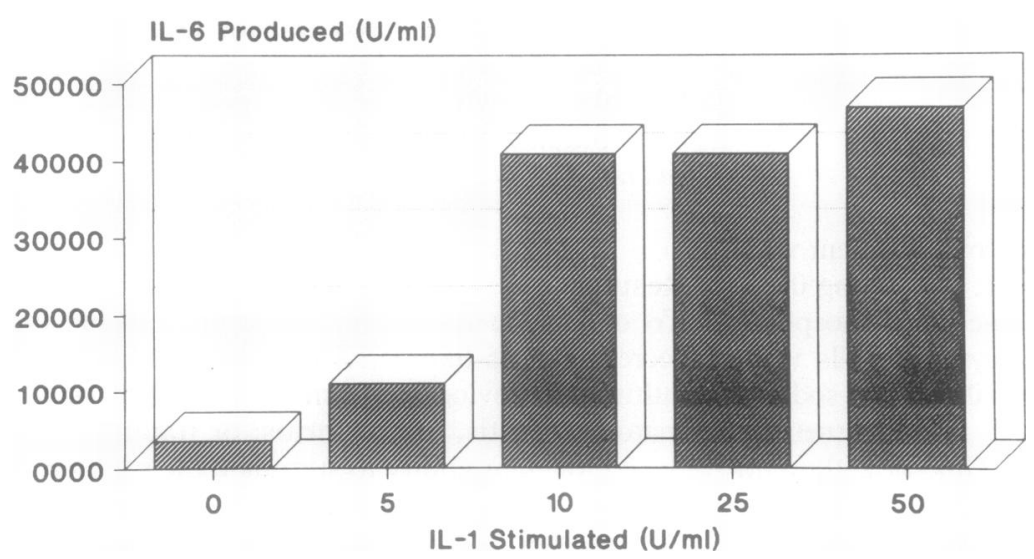

Figure I Supernatant from synoviocytes derived from a patient with trauma was tested for its ability to induce the proliferation of the B9 mouse plasmacytoma cell line. Conditioned medium induced proliferation as indicated by enhanced thymidine uptake. Results are expressed as units of interleukin 6 (IL-6) activity with one unit of activity defined as the amount of $I L-6$ required to induce $50 \%$ of the maximum stimulation. The ability of synoviocyte conditioned medium to induce plasmacytoma proliferation was markedly enhanced in a dose dependent manner by culturing the synoviocytes with IL-1 for 48 hours.

\section{CPM}

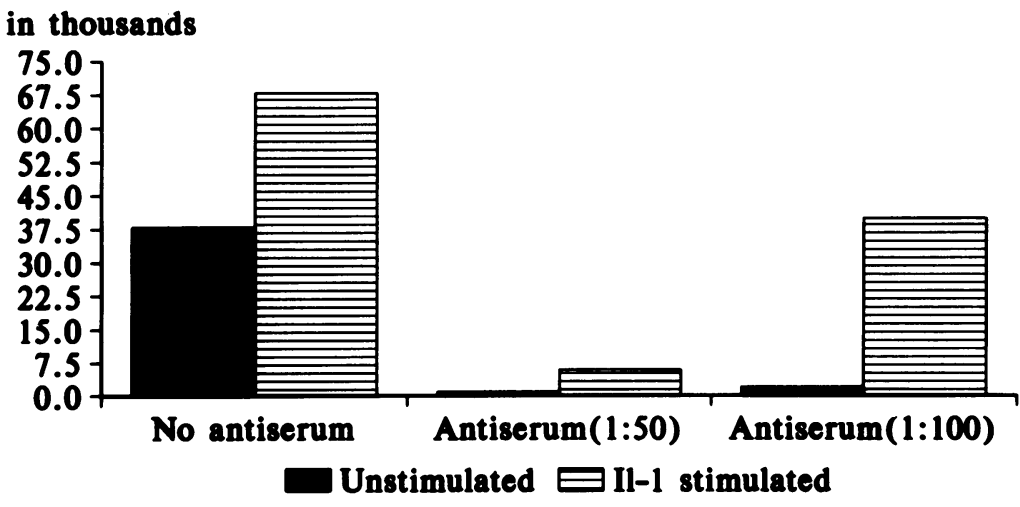

Figure 2 Synoviocytes from a patient with rheumatoid arthritis were cultured in medium with or without interleukin $1(I L-1)(30 U)$. Tested at a 1:64 dilution, this conditioned medium induced the proliferation of B9 cells. A polyclonal antiserum to IL-6 at a dilution of 1:50 or 1:100 inhibited the proliferative activity in conditioned medium. The partial inhibition of proliferative activity in conditioned medium from IL-1 stimulated cells suggests that the antiserum is not toxic to plasmacytoma cells and that greater IL-6-like activity is detectable after IL-1 stimulation.

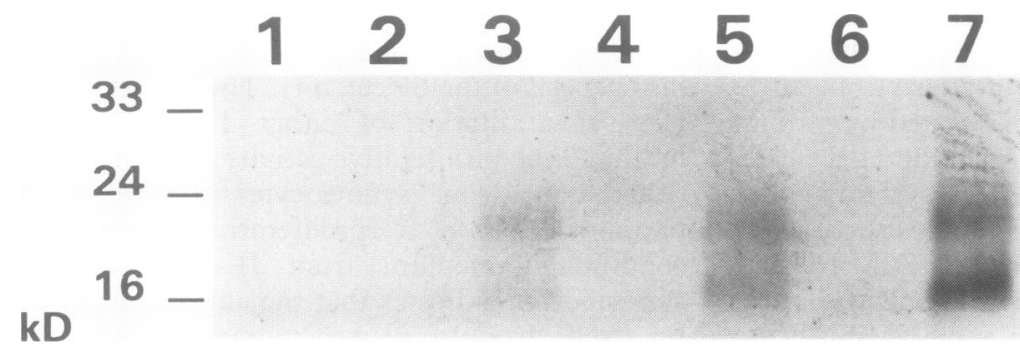

Figure 3 Western blot analysis was performed as described under Methods. The locations of molecular weight standards are marked by a bar and the relative size in kilodaltons $(k D)$. Lane 1 contains 4 ng of the standard interleukin 6 (IL-6). Lanes 2, 4, and 6 contain medium conditioned for 48 hours by synoviocytes derived from patients with trauma, rheumatoid arthritis, and osteoarthritis. Lanes 3, 5 and 7 are supernatants from synoviocytes from the same three patients after stimulation with IL-I (30 U) for 48 hours.
Effect of diagnostic class on synthesis of IL-6. Stimulated synoviocytes were cultured with recombinant human $I L-I \alpha$ $(30 U)$ for 48 hours; unstimulated and stimulated cells were incubated with Dulbecco's modified Eagle's medium in the presence of $10 \%$ calf serum. Results are given as mean (standard error).

\begin{tabular}{lll}
\hline $\begin{array}{l}\text { Source of } \\
\text { synoviocyte }\end{array}$ & $\begin{array}{l}\text { IL-6 synthesis in } \\
\text { unstimulated } \\
\text { synoviocytes } \\
(U / m l)\end{array}$ & $\begin{array}{l}\text { IL-6 synthesis in } \\
\text { IL-l stimulated } \\
\text { synoviocytes } \\
(\text { U/ml })\end{array}$ \\
\hline $\begin{array}{l}\text { Patients with rheumatoid } \\
\text { arthritis }(\mathrm{n}=5)\end{array}$ & $2080(749)$ & $70000(13390)$ \\
$\begin{array}{l}\text { Patients with osteoarthritis } \\
(\mathrm{n}=4)\end{array}$ & $1900(750)$ & $48750(12650)$ \\
$\begin{array}{l}\text { Patients with joint trauma } \\
(\mathrm{n}=4)\end{array}$ & $1000(216)$ & $43000\left(\begin{array}{ll}10 & 120\end{array}\right)$ \\
\hline
\end{tabular}

weights of 19000 to 24000 which reacted with the antibody to IL-6. The IL-6-like peptides were detectable only after stimulation by IL-1.

The potential of synoviocytes to synthesise IL-6 was studied further by Northern blot analysis. A $1 \cdot 3 \mathrm{~kb}$ messenger RNA from primary synoviocyte cultures grown in the presence of $10 \%$ calf serum consistently hybridised to a cDNA probe specific for IL-6 (data not shown). Cultures from 12 different patients (three with rheumatoid arthritis, three with osteoarthritis, and six with trauma) were studied by Northern blot analysis for the presence of IL- 6 mRNA. The transcript was detectable in all synovial cultures stimulated by serum. The induction of mRNA began within three hours of serum stimulation and lasted for at least 24 hours. Densitometry readings in representative studies indicated that the serum at least tripled the level of detectable mRNA specific for IL-6.

Consistent with the previous functional data and Western blot analysis, the IL- 6 mRNA could be induced by culturing the cells with IL-1. Figure 4 shows that synoviocytes from a patient with rheumatoid arthritis, when cultured in the presence of IL-1 for 48 hours, expressed a markedly increased level of IL-6 mRNA. In addition to the $1.3 \mathrm{~kb}$ transcript, further minor bands are detectable after IL-1 stimulation. These have been reported for other cell lines and may represent an IL-6 precursor, degradation products, or the effect of alternate mRNA splicing. To determine that the apparent difference in IL-6 expression in the presence of IL-1 was not due to the unequal loading of lanes with amounts of mRNA, blots were re-probed with a cDNA for cyclophilin, a message which is constitutively expressed by a wide variety of tissues. $^{24}$ These studies indicated that the enhanced detection of IL- 6 mRNA could not be ascribed to the unequal loading of mRNA. In studies not shown here, the ability of IL-1 to induce mRNA was more marked at 48 hours than with culture for three or 18 hours.

Insulin $(166 \mathrm{ng} / \mathrm{ml})$ or basic fibroblast growth factor $(16 \mathrm{ng} / \mathrm{ml})$ also increased IL-6 mRNA expression approximately six fold. Figure 5 shows that the combination of insulin, fibroblast growth factor, and a small concentration of calf serum $(0.33 \%)$ had a greater effect than any of these stimuli alone. In three separate studies (not shown), basic fibroblast growth factor by itself $(16 \mathrm{ng} / \mathrm{ml})$ increased the expression of IL-6 mRNA expression approximately three fold. Culturing synoviocytes in the presence of 


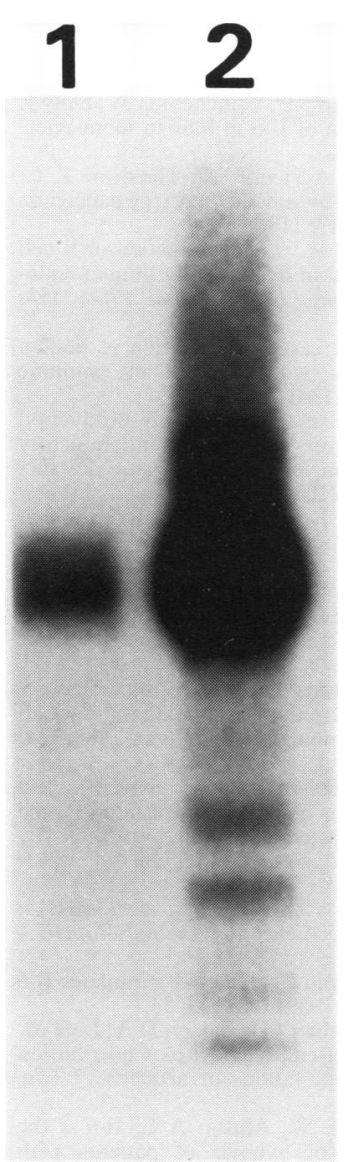

Figure 4 Northern blot analysis was performed on synoviocytes from a patient with rheumatoid arthritis. Synoviocytes whose RNA was electrophoresed in lane 1 were cultured in the presence of $20 \%$ fetal calf serum for 48 hours. In lane 2, the RNA was obtained from the identical synviocyte line cultured in the presence of $20 \%$ fetal calf serum plus interleukin 1 (30 U) for 48 hours. Polyadenylated RNA was electrophoresed at $5 \mu \mathrm{g}$ per lane.
IL-6 $(12.5 \mathrm{U} / \mathrm{ml})$ failed to induce detectable expression of IL-6 mRNA (fig 5). Dexamethasone $\left(10^{-6} \mathrm{~mol} / \mathrm{l}\right)$ was able to abrogate the induction of IL-6 mRNA by either IL-1 or calf serum, but it had little effect on the constitutive expression of IL-6 mRNA. These results were seen in three of four cultures stimulated by IL-1 and in seven of nine cultures stimulated with serum.

\section{Discussion}

These studies indicate that synoviocytes from patients with rheumatoid arthritis, osteoarthritis, or trauma synthesise an IL-6-like molecule based on the results of Northern blots to detect mRNA, Western blot to detect immunologically reactive peptides, and plasmacytoma proliferation assays to detect biological activity. This peptide appears to be induced by IL-1, insulin, basic fibroblast growth factor, or serum, but its expression is not detectably affected by IL-6 itself. IL-1 has been reported to be an effective stimulus for IL-6 synthesis in several cell types. ${ }^{25}$ Dexamethasone inhibited the stimulatory effects of either serum or IL-1. This report confirms three previous studies ${ }^{26-28}$ indicating that synoviocytes synthesise IL-6, and extends those studies through Northern blot analysis and observations on the regulation of IL-6. Two groups have used the technique of in situ hybridisation to detect mRNA specific for IL-6 in synovial tissue from patients with rheumatoid arthritis. ${ }^{28} 29$

Basic fibroblast growth factor is a widely synthesised polypeptide. Its tissue sources include synoviocytes and monocytes. ${ }^{21}$ At least three other polypeptide growth factors, platelet derived growth factor, ${ }^{30}$ transforming growth factor $\beta,{ }^{27}$ and epidermal growth factor (in concert with tumour necrosis factor $\alpha)^{31}$ increase the expression of IL-6 mRNA. We believe that this is the first report that implicates basic fibroblast growth factor in the regulation of a cytokine involved in the immune response.
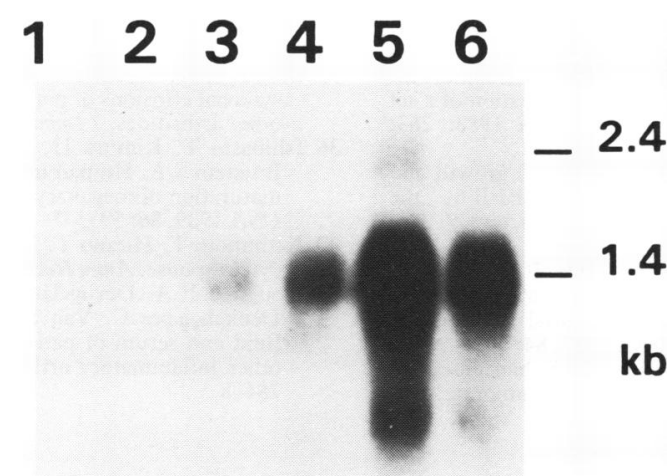

Figure 5 Synoviocytes derived from a patient with rheumatoid arthritis were cultured for three hours in medium only (lane 1), interleukin 6 (IL-6) $(12 \cdot 5 U)$ (lane 2), insulin (166 ng/ml) (lane 3), insulin plus basic fibroblast growth factor $(16 \mathrm{ng} / \mathrm{ml})$ (lane 4), insulin plus fibroblast growth factor plus $0.33 \%$ calf serum (lane 5), or calf serum alone (lane 6). Total RNA was extracted, electrophoresed, transferred, and probed with a cDNA specific for IL-6. The major detectable transcript is $1.3 \mathrm{~kb}$ based on a size scale as noted by the bars. Lanes depicted in the figure have been selected from a larger gel. Each lane contains $16 \mu \mathrm{g}$ of RNA.
Cytokines such as IL-1 and tumour necrosis factor $\alpha$ have functions (such as stimulating the proliferation of fibroblasts) which extend outside the immune system. Conversely, several of the polypeptide growth factors such as transforming growth factor $\beta^{32}$ and basic fibroblast growth factor may have functions that overlap or modulate the interleukins and other cytokines.

A variety of cytokines and growth factors appear to be synthesised by the fibroblast-like synoviocyte population. These cytokines include IL- $1^{2}$ and basic fibroblast growth factor. ${ }^{21}$ Other cytokines such as transforming growth factor $\beta^{33}$ and granulocyte macrophage colony stimulating factor are apparently present in synovial fluid, ${ }^{34}$ although their cellular source is not as clearly defined.

The Western blot studies detect at least two peptides immunologically reactive with antibodies to IL-6. A recent report indicates that fibroblasts and monocytes synthesise at least five forms of IL-6 with molecular weights ranging between 23000 and $30000 . .^{23}$ Several forms of IL-6 have previously been reported in synovial fluid. ${ }^{35}$ Different forms of IL-6 may vary markedly in specific biological activities.

The biological activities of IL-6 suggest that it could contribute to the process of inflammation characteristic of rheumatoid arthritis. The capacity to act as a cofactor for $\mathrm{T}$ cell activation and the ability to stimulate immunoglobulin secretion could be important contributions to inflammatory joint disease. By stimulating the synthesis of acute phase proteins, IL-6 may contribute to the raised erythrocyte sedimentation rate characteristic of rheumatoid arthritis. By stimulating megakaryocytes, ${ }^{36}$ IL-6 may be responsible for the thrombocytosis that is highly characteristic in patients with rheumatoid arthritis.

If IL-6 is a significant contributor to rheumatoid arthritis, it must be explained why significantly more IL-6 is not produced by synoviocytes derived from patients with rheumatoid arthritis. As synoviocytes from patients with rheumatoid arthritis tend to make more IL-6 than control synoviocytes (table), conceivably a study with a larger number of patients might have shown statistically significant differences. Clearly, however, a large overlap exists such that the in vitro synthesis of IL-6 does not readily distinguish among synoviocytes from the three diagnostic groups: rheumatoid arthritis, osteoarthritis, and trauma.

Our results appear to contradict several reports that found IL-6 more readily in synovial fluid in patients with rheumatoid arthritis compared with those with osteoarthritis. ${ }^{2630} 3738$ A study using in situ hybridisation was able to detect more IL-6 mRNA expressed by synoviocytes from patients with rheumatoid arthritis relative to those with osteoarthritis. ${ }^{28}$ However, tissue culture conditions tend to activate synoviocytes, allowing the replication of cells which are normally quiescent. This is equally true of cells derived from inflammatory diseases and cells derived from patients with trauma. Accordingly, we have study activated synoviocytes. The failure to detect enhanced IL-6 in 
rheumatoid as opposed to osteoarthritis synoviocytes suggests that exaggerated IL- 6 synthesis is not the primary defect in rheumatoid arthritis.

Our data indicate that synoviocytes from different disease states are capable of synthesising this mediator and therefore suggest that IL-6 synthesis is a secondary phenomenon that may contribute to the pathogenesis of joint inflammation. For example, infiltrating lymphocytes, which are commonly present in the synovium of patients with rheumatoid arthritis, could provide signals to stimulate cytokine production by synoviocytes. Our data agree with those reported by Guerne et al, ${ }^{26}$ who found that synovial fluid from patients with rheumatoid arthritis contained greater amounts of IL-6 compared with fluids from patients with osteoarthritis, but that in vitro production by synoviocytes from either disease state was similar.

This work was supported in part by NIH grant EY07373, the Gerlinger Foundation, the Fund for Arthritis and Infectious Disease Research of the Kuzell Institute, San Francisco and Veteran's Administration Merit Review Award to Dr Hefeneider.

1 Nouri A M E, Panayi G S, Goodman S M. Cytokines and the chronic inflammation of rheumatic disease. I. The presence of interleukin-1 in synovial fluids. Clin Exp Immunol 1984 55: 295-302.

2 Goto M, Sasano M, Yamanaka H, et al Spontaneous produc tion of an interleukin-1 like factor by cloned rheumatoid synovial cells in long-term culture. $\mathcal{f}$ Clin Invest 1987; 80: 786-96.

3 Kumkumian G K, Lafyatis R, Remmers E F, Case J P Kim S J, Wilder R L. Platelet-derived growth factor and IL-1 interactions in rheumatoid arthritis. Regulation of IL-1 interactions in rheumatoid arthritis. Regulation of synoviocyte proliferation, prostaglandin production,

4 Miossec $P$. The role of interleukin-1 in the pathogenesis of rheumatoid arthritis. Clin Rheumatol 1987; 5: 305-8.

5 Dinarello C A. Interleukin-1 and its biologically related cytokines. Adv Immunol 1989; 44: 153-205.

6 Helle M, Boeije L, Aarden L A. II-6 is an intermediate in II-1-induced thymocyte proliferation. $\mathcal{F}$ Immunol $1989 ; 142$ 4335-8.

7 Helle M, Brakenhoff J P, DeGroot E R, Aarden L A. Interleukin 6 is involved in interleukin 1-induced activities. Eur f Immunol 1988; 18: 957-9.

8 Ray A, Tatter S B, May L T, Sehgal P B. Activation of the human "b2-interferon/hepatocyte-stimulating factor/ human "b2-interferon/hepatocyte-stimulating factor/ interleukin 6" promoter by cytokines, viruses, and second messeng.

9 Tosato G, Pike S E. Interferon-b2/interleukin 6 is a co-stimulant for human T lymphocytes. $\mathcal{F}$ Immunol 1988 141: 1556-62.

10 Jirik F R, Podor T J, Hirano T, et al. Bacterial lipopolysaccharide and inflammatory mediators augment II- 6 secretion by human endothelial cells. F Immunol 1989; 142 $144-7$.

11 Morrone G, Ciliberto G, Oliviero S, et al. Recombinant interleukin 6 regulates the transciptional activation of a set of human acute phase genes. 7 Biol Chem 1988; 263: $12554-8$.

12 Uyttenhove C, Coulie P G, Van Snick J. T cell growth and differentiation induced by interleukin-HPI/II-6, the murine hybridoma/plasmacytoma growth factor. $\mathscr{f}$ Exp Med 1988; 167: 1417-27.

13 Ikebuchi K, Wong G G, Clark S C, Ihle J N, Hirai Y, Ogawa M. Interleukin 6 enhancement of interleukin 3-dependent proliferation of multipotential hemopoietic

14 Zhang Y, Lin J-X, Yip Y K, Vilcek J. Enhancement of cAMP levels and of protein kinase activity by tumor necrosis factor and interleukin 1 in human fibroblasts: role in the induction of interleukin 6. Proc Natl Acad Sci USA 1988 85: 6802-5.

15 Navarro S, Debili N, Bernaudin J-F, Vainchenker W, Doly J. Regulation of the expression of II- 6 in human monocytes. F Immunol 1989; 142: 4339-45.

16 Campbell I L, Angelina C, Adrienne W, Harrison L C. Evidence for II-6 production by and effects on the pancreatic beta cell. F Immunol 1989; 143: 1188-91.

17 Norioka K, Hara M, Harigai M, et al. Production of B cell stimulatory factor-2/interleukin 6 activity by human endothelial cells. Biochem Biophys Res Commun 1988; 153: 1045-50.

18 Brinckerhoff C, Guyre P. Increased proliferation of human synovial fibroblasts treated with recombinant immune interferon. F Immunol 1985; 134: 3142-6.

19 Wahl S M, Malone D G, Wilder R L. Spontaneous production of fibroblast-activating factors by synovial inflammatory cells. A potential mechanism for enhanced tissue destruction. F Exp Med 1985;161: 210-22.

20 Helle M, Boeije L, Aarden L. Functional discrimination between interleukin 6 and interleukin 1. Eur $\mathcal{F}$ Immuno 1989; 18: 1535-40

21 Melnyk V O, Shipley G D, Sternfeld M D, Sherman L Rosenbaum J T. Synoviocytes synthesize, bind, and respond to basic fibroblast growth factor. Arthritis Rheum. 1990; 33: 493-500.

22 Hirano T, Yasukawa $\mathrm{K}$, Harada $\mathbf{H}$, et al. Complementary DNA for a novel human interleukin (BSF-2) that induces B lymphocytes to produce immunoglobulin. Nature 1986; 324 : 73-6.

23 May L T, Ghrayeb J, Santhanam U, et al. Synthesis and secretion of multiple forms of beta 2 -interferon/B cell differentiation factor 2 /hepatocyte-stimulating factor by differentiation factor 2 /hepatocyte-stimulating factor by 7760-6.

24 Danielson P E, Forss-Petter S, Brow M A, et al. plB15: a cDNA clone of the rat mRNA encoding cyclophilin. DNA 1988; 7: 261-7.

25 Sironi M, Breviario F, Proserpio P, et al. Il-1 stimulates II-6 endothelial cells. F Immunol 1989; 142: 549-53.

26 Guerne P-A, Zuraw B L, Vaughan J H, Carson D A, Lotz M Synovium as a source of interleukin 6 in vitro. Contribution to local and systemic manifestations of arthritis. $\mathcal{f} \mathrm{Clin}$ Invest 1989; 83: 585-92.

27 Nawata Y, Eugui E M, Le S W, Allison A C. Il-6 is the principal factor produced by synovia of patients with rheumatoid arthritis that induces B-lymphocytes to secrete immunoglobulins. Ann NY Acad Sci 1989;557: 230-9.

28 Firestein G S, Alvaro-Garcia J M, Maki R. Quantitative analysis of cytokine gene expression in rheumatoid arthritis. analysis of cytokine gene expression

29 Ogilvie A D, Wood N C, Dickens E, Wojtacha D, Duff G W In situ hybridisation. Ann Rheum Dis 1990; 49: 434-9.

30 Hirano T, Matsuda T, Turner M, et al. Excessive production in interleukin $6 / \mathrm{B}$ cell stimulatory factor- 2 in rheumatoid arthritis. Eur F Immunol 1988; 18: 1797-1801

31 Mawatari M, Kohno K, Mizoguchi $\mathrm{H}$, et al. Effects of tumo necrosis factor and epidermal growth factor on cell morphology, cell surface receptors, and the production of tissue inhibitor of metalloproteinases and II- 6 in human microvascular endothelial cells. F Immunol 1989; 143: 1619-27.

32 Chantry D, Turner M, Abney E, Feldmann M. Modulation of cytokine production by transforming growth factor B1. of cytokine production by transford

33 Fava R, Olsen N, Keski-Oja J, Moses M, Pincus T. Active and latent forms of transforming growth factor beta activity in a synovial effusion. $\mathcal{E}$ Exp Med 1989; 169: 291-6.

34 Xu W D, Firestein G S, Taetle R, Kaushansky K, Zvaifler $\mathrm{N}$ J. Cytokines in chronic inflammatory arthritis. II Granulocyte-macrophage colony-stimulating factor in rheumatoid synovial effusions. F Clin Invest 1989; 83: 876-82.

35 Bhardwaj N, Santhanam U, Lau L L, et al. Il-6/IFN-B2 in synovial effusions of patients with rheumatoid arthritis and other arthritides. F Immunol 1989; 143: 2153-9.

36 Ishibashi T, Kimura H, Uchida T, Kariyone S, Friese P Burstein S A. Human interleukin-6 is a direct promoter of maturation of megakaryocytes in vitro. Proc Nat Acad Sci USA 1989; 86: 5953-7.

37 Kishimoto T, Hirano T. Molecular regulation of B lymphocyte response. Annu Rev Immunol 1988; 6: 485-512.

38 Houssiau F A, Devogelaer J-P, Van Damme J, Nagant de Deuxchaisnes C, Van Snick J. Interleukin-6 in synovial Deuxchaisnes C, Van Snick J. Interleukin-6 in synovial fluid and serum of patients with rheumatoid arthritis and other infla 